\title{
Projetos de inclusão social através do esporte: notas sobre a avaliação
}

\author{
José Antonio Vianna*
}

Hugo Rodolfo Lovisolo**

\begin{abstract}
Resumo: Os objetivos dos projetos esportivos são orientados para a inclusão social. A partir de pesquisas já realizadas sobre a participação das camadas populares através do esporte - tomando por campo empírico principal o Projeto de Inclusão Social (PIS), situado na Cidade de Deus, Rio de Janeiro -, objetiva-se analisar e discutir o valor dos dados administrativos dos programas, para darem conta de problemas relevantes (adesão e rotatividade). Trata-se de refletir e apontar caminhos de refinamento dos dados administrativos dos programas. A experiência contou com uma base significativa, quantitativa e temporal: 6.932 fichas de inscrição, referentes a 5.462 participantes.
\end{abstract}

Palavras-chave: Esportes. Iniquidade social. Avaliação.

\section{INTRODUÇÃO}

O reconhecimento do esporte como canal de socialização positiva ou inclusão social, é revelado pelo crescente número de projetos esportivos destinados aos jovens das classes populares, financiados por instituições governamentais e privadas. Na literatura em educação física, esportes e lazer, sociologia e em outras áreas, são apresentadas indicações dos benefícios proporcionados pela prática regular de esportes, na formação moral ou da personalidade dos seus praticantes (ELIAS; DUNNING, 1992; DANISH; NELLEN, 1997; TUBINO, 2001). Assim, crenças tradicionais sobre a função do esporte, elaboradas no século XIX, e, não raro, influenciadas por elaborações mais antigas, pareceriam voltar com força na atualidade. Um exemplo interessante da nova linguagem pode ser observado na comparação

\footnotetext{
Doutor pela Universidade Estácio de Sá. Rio de Janeiro, RJ. Brasil. E-mail: javianna@hotmail.com "” Doutor pela Universidade do Estado do Rio de Janeiro. UNISUAM. Rio de Janeiro, RJ. Brasil. E-mail: lovisolo@globo.com
} 


\section{Antigor Originais}

José Vianna, Hugo Lovisolo

entre a denominação dada por Dom Bosco aos jovens da rua, ainda no século XIX, e a linguagem atual. ${ }^{1}$ Ele os denominava "periclitantes", isto é, podiam caminhar para o mal ou para o bem. Sua tarefa missionária, e a dos futuros salesianos, era a de criar condições para que fossem na direção do bem, mediante educação e atividades que incluíam jogos e esportes em um clima de "vigilância afetuosa". ${ }^{2}$ Hoje em dia, dominados pela linguagem securitária e epidemiológica, os programas frequentemente classificam as crianças e o jovem, que passam parte significativa do dia na rua ou que nela moram, como estando em situação de "risco". Os riscos do fracasso escolar, da evasão, da droga, do sexo sem prevenção, da carreira na delinquência e dos acidentes, entre outros, são agitados para se dizer que se tem de tirar as crianças da rua e colocá-las em ambientes controlados, estimuladores e educativos. Embora exista diferença entre periclitância e risco o plano da continuidade está fortemente presente.

Nos últimos anos, a participação de atletas de destaque, sobretudo oriundos do futebol, pelo próprio peso social do mesmo, na criação de organizações dedicadas a ofertar atividades esportivas e culturais para crianças e jovens das camadas populares é um indicador privilegiado da força do complexo de crenças esboçadas sobre o esporte. Todavia, a dedicação a tal tipo de atividades pode ser entendida ou justificada tanto a partir da responsabilidade social quanto da devolução, reciprocidade ou gratidão pelo apoio e pelos benefícios recebidos pelo atleta ao longo de sua carreira. Não raro, os atletas criam os centros onde desenvolvem seus projetos em suas comunidades de origem e realizam declarações entusiastas sobre eles. As atitudes dos atletas devem ser estimuladas e apoiadas. O que está em foco são algumas observações sobre como se pode refinar os dados para se ter um melhor entendimento dos efeitos dos projetos.

A mídia, no Brasil, por seu lado, aparece enfatizando quatro grandes grupos de benefícios das práticas esportivas que espelham

\footnotetext{
${ }^{1}$ As Teses de Doutorado de Silva (2002) e Borges (2005) abordam a prática de atividades físicas em escolas religiosas.

2 Traduziu-se o termo "amorevoleza" central na pedagogia salesiana por "vigilância afetuosa".

Movimento, Porto Alegre, v. 15, n. 03, p. 145-162, julho/setembro de 2009.
} 
as propostas teóricas e políticas: as possibilidades de profissionalização, a formação estética dos corpos, o impacto positivo sobre a saúde e o campo multifacético do lazer, da sociabilidade, do entretenimento. Entretanto, parece existir uma contradição entre a amplidão e aparente profundidade das crenças que as pessoas possuem sobre seus benefícios e a baixa adesão à atividade física sistemática. Notável, por exemplo, são as declarações de crianças e jovens no sentido de serem profissionais do esporte e, particularmente, do futebol. $\mathrm{O}$ apoio midiático e as declarações de crianças e jovens destacam a importância dos questionamentos sobre a "não adesão" e as propostas como foco de investigação para se compreenderem seus processos. A "não adesão" poderia ser lida tanto nos percentuais baixos de participação das atividades, quando se estima o percentual de participação efetiva sobre a participação potencial, quanto nas altas taxas de abandono e, muito especialmente, no tempo médio efetivo de permanência nas atividades do programa.

A experiência de trabalho de campo indica que é difícil a obtenção do tipo de dados necessários para as questões em pauta. O pesquisador, por vezes, tem a impressão de que os coordenadores ou dirigentes dos projetos pensam apenas em termos de número total de participante sem, por exemplo, levar em conta as taxas de rodízio dos programas ou projetos nem o matriculado por longo tempo ausente. A demanda alta pode ocultar a "saída" ou abandono das atividades. Sob o ponto de vista do administrador, se sempre há alguém disposto a se matricular ou, então, se saídas e entradas se compensam, para que entender àqueles que abandonam ou que estão durante longo tempo ausentes? De fato, se o tempo médio de permanência no programa for baixo, diga-se, menos que seis meses, os objetivos pretendidos serão de impossível realização para a maioria dos matriculados. Torna-se difícil justificar a formação esportiva ou moral em períodos tão curtos. No entanto, fica também difícil criar mecanismos mais ou menos duradouros de adesão à atividade física. Enfim, objetivos generosos parecem estar em situação de "risco" diante de condutas como as mencionadas.

As tentativas de explicação para os níveis relativamente baixos de adesão são realizadas, sobretudo por aqueles que se incluem na

Movimento, Porto Alegre, v. 15, n. 03, p. 145-162, abril/junho de 2009. 


\section{Antigor Orifinais}

José Vianna, Hugo Lovisolo

tribo da saúde, isto é, que predicam a relação entre atividade física e saúde. Os principais argumentos para explicar a baixa adesão à atividade física são de dois tipos: condições e consciência, isto é, econômicos, sociais e culturais. Os que acreditam na falta de condições têm multiplicado significativamente os equipamentos e as ofertas no Brasil. Os que apostam na intencionalidade reforçam as campanhas para motivar a prática e conscientizar sobre sua necessidade e seus benefícios (LOVISOLO, 2002a; 2002b).

Predominantemente, as pesquisas que se ocupam de condições e motivos da adesão têm por informantes sujeitos adultos. As respostas dadas para a não adesão estão gastas sob o ponto de vista de que levam a realizar o mesmo tipo de ações, no presente, que se revelaram pouco eficientes no passado. Entretanto, as coisas deveriam ser diferentes com crianças e jovens, pois acredita-se na existência de uma afinidade eletiva entre eles e o esporte, o movimento, o jogo.

No caso dos programas para crianças e jovens, embora a linguagem da conscientização também os percorra, pareceria que necessita-se de outro tipo de entendimento. Parece um tanto despropositado recomendar para uma criança de 10 anos que, se não faz atividade física de forma sistemática, quando envelhecer, terá condições piores de vida. Além das possíveis traduções da recomendação, melhores ou piores, elas não pareceriam fazer muito sentido, sob o ponto de vista dos 10 anos. Então, a não adesão ao tipo de programa em discussão deveria procurar outras hipóteses de entendimento, tanto da baixa participação quanto do alto rodízio. Talvez, aproximar formas de entendimento e pesquisa com, por exemplo, a resistência às aulas de atividade física no contexto escolar. $\mathrm{O}$ que parece evidente, após longa experiência, é que a prédica da pastoral da atividade física tem baixa influência quando vista a partir dos objetivos dos predicadores.

Assim, emerge a necessidade de compreensões ou explicações alternativas para os altos índices de não praticantes e, o que parece ser mais estratégico, para a desistência a partir da experiência pessoal das práticas esportivas e de suas autoavaliações. Especificamente, corresponde se interrogar sobre tais ocorrências no caso dos

Movimento, Porto Alegre, v. 15, n. 03, p. 145-162, julho/setembro de 2009. 
programas destinados a crianças e jovens das camadas populares. A plena ocupação da oferta não implica o desaparecimento dos problemas, como tentar-se-á mostrar.

As entidades financiadoras e orientadoras de programas sócioesportivos para as camadas mais vulneráveis da população brasileira, parecem apenas vislumbrar as possibilidades do esporte como um caminho para a realização das expectativas dos sujeitos e não se interrogam sobre as possibilidades de frustração. Acredita-se que o entusiasmo generoso dos promotores leva a enfatizar apenas as realizações, jamais o lado escuro das frustrações. O mapeamento dos PIS elaborado por Gomes e Constantino (2005), no Atlas do Esporte no Brasil, não explica os motivos para o envolvimento dos participantes e não relatam os pormenores da prática. Os autores utilizaram informações fornecidas pelas entidades gestoras de PIS que, em sua maioria, informam o número de sujeitos que ingressaram, sem preocupação com o seu período de permanência, o que possivelmente revelaria o enorme abandono e rotatividade dos participantes (SILVA MELLO; LOVISOLO; VOTRE, 2008). Em recente análise de programa supostamente envolvente (SOARES; DUARTE, 2007), por irem da capacitação empresarial à inserção social, passando por atividades físicas, chegam a conclusões semelhantes: apesar das qualidades do programa, o abandono é alto.

Pode-se supor que assim como o fracasso escolar leva ao abandono da escola, o fracasso esportivo - a não obtenção do desempenho esperado ou desejado a custos psicológicos ou fisiológicos altos - poderia levar ao abandono da prática. Observe-se que a prática escolar da "promoção automática" ou "promoção continuada" procurou lidar com a cadeia "fracasso-abandono", entretanto, a "promoção automática" no esporte parece impossível ou pouco eficaz, pois, os olhos de cada participante constatam o nível de desempenho. No campo esportivo infantil, distribuir uma medalha para cada participante foi uma solução aparente para o fracasso em relação às expectativas. A experiência com os filhos indica que ganhar uma medalha, embora sem ganhar a prova, não é igual a ganhar a competição. Mais ainda, a satisfação de ganhar a medalha por haver participado perde sua força com o aumento da idade.

Movimento, Porto Alegre, v. 15, n. 03, p. 145-162, abril/junho de 2009. 


\section{Antifor Originais}

José Vianna, Hugo Lovisolo

A relação entre crenças e experiências dos praticantes deve ser observada e analisada contextualmente. Promover acordos entre as crenças e as práticas implica processos de elaboração social, de acordos simbólicos, que apenas podem ser realizados em nível local (LOVISOLO, 1995). Implica a mediação ativa entre valores e objetivos, motivos, e a avaliação dos resultados da experiência, sobretudo, no início dos processos de mudança de crenças e condutas.

Em investigação realizada em 2005, procurou-se pesquisar a formulação de explicações alternativas (VIANNA; LOVISOLO, 2005) para a elaboração social em contextos específicos. Duas constatações, embora gerais, foram realizadas naquele momento: a) existem diversas concepções sociais coexistentes acerca da influência da prática orientada de atividades físicas e b) os sujeitos realizam arranjos das crenças e tomam decisões em função dos sinais ou respostas de suas experiências práticas. Portanto, o lugar da crença entre as crenças, sua posição hierárquica, é influenciado pelas experiências práticas das pessoas. Entende-se que falar da "experiência própria" já implica algum grau de avaliação reflexiva do desempenho pessoal.

Apesar do crescimento no número de projetos, a teorização que existe atualmente sobre as relações do esporte com grupos submetidos a riscos ou marginalizados pela pobreza não parece atentar para o que diz respeito ao entendimento das racionalidades locais dos indivíduos, e de seus motivos para a ação e das avaliações que reforçam ou modificam motivos e práticas iniciais. Na verdade, esquece-se com frequência de que não se trata de saúde abstrata ou de esporte em geral, trata-se de uma saúde situada, qualificada e de um esporte significado a partir das interações locais.

Na tentativa de contribuir para a compreensão do fenômeno em pauta, propôs-se observar a "adesão" de jovens das camadas populares às atividades esportivas extraescolares, tendo como cenário um Projeto de Inclusão Social (PIS) através do esporte. A observação, de caráter exploratório, foi realizada em um núcleo de atividades extracurriculares de atividades físicas e culturais situado no interior da favela Cidade de Deus, no município do Rio de Janeiro, em funcionamento desde 1993.

Movimento, Porto Alegre, v. 15, n. 03, p. 145-162, julho/setembro de 2009. 
Os objetivos da observação foram: a) avaliar a entrada, permanência e saída dos jovens nos grupos de atividades físicas e culturais, b) observar a intensidade do envolvimento e c) verificar se existem diferenças na adesão dos participantes por gênero.

Acredita-se que a descrição e compreensão dos aspectos enunciados poderiam realimentar as intervenções, refinando sua coerência com as dinâmicas locais, favorecendo os acordos entre as propostas institucionais e as aspirações dos agentes do processo de intervenção.

\section{DAS INFORMAÇÕES}

A coleta de informações foi realizada a partir de 6.932 fichas de inscrição, referentes a 5.462 alunos de ambos os sexos, na faixa etária de cinco a 24 anos, matriculados no projeto no período de 1998 a 2003. A diferença (1460) entre as fichas de inscrição e o número de alunos implica o montante de reinscrição. As fichas identificavam o aluno com dados de endereço, idade, gênero, escola e série. Nas mesmas, eram registradas as atividades praticadas e a frequência semanal. Anualmente, os participantes renovavam a sua matrícula, informando o nome, ano de nascimento, sexo, nome dos responsáveis e/ou filiação, instituição em que o aluno estudava, série, turma e atividades que desejava praticar. Os dados levantados permitiram identificar a quantidade de escolas atendidas; o número de sujeitos por atividade e gênero; a quantidade de alunos por idade e série escolar; e a quantidade de alunos por anos de prática nas diversas atividades oferecidas. As informações sobre adesão e evasão dos participantes, verificadas nos dados cadastrais, favoreceram a focalização das pessoas mais representativas para o assunto investigado na tese de doutorado de Vianna (2007).

\section{Resultados E discussão}

A localização do PIS - situado dentro da favela, no prédio da Associação de Moradores - parece ter facilitado o acesso dos participantes, por não necessitarem de transporte. As ruas planas tinham

Movimento, Porto Alegre, v. 15, n. 03, p. 145-162, abril/junho de 2009. 


\section{Antigor Orifinais}

José Vianna, Hugo Lovisolo

pouca movimentação de automóveis, favorecendo a utilização de bicicletas para o deslocamento dos que moravam mais afastados. Apesar dos fatores favoráveis, pode-se constatar, na Tabela 1, tomando como base o número total de sujeitos (não de matrícula), que quase $80 \%$ permaneceu no programa por menos de um ano e quase $16 \%$ entre um e dois anos. No outro extremo da distribuição, os participantes com idade entre cinco e seis anos, apenas significavam $0,02 \%$. Este pequeno percentual ainda faria sentido se o objetivo do programa fosse a formação de atletas mediante processos técnicos de seleção. Porém, este não é o caso! Portanto, os dados indicam um alto abandono ou uma baixa capacidade do programa em reter os participantes. O tempo curto de permanência levanta dúvidas sobre a possibilidade de realização efetiva dos objetivos do programa, especialmente os que envolvem processos de socialização e de criação de hábitos, para aproximadamente $95 \%$ dos participantes. Pode-se inferir que o número total de participantes é um indicador muito fraco na avaliação dos programas que, de modo geral, têm por objetivo mais amplo a inclusão social. Mais ainda, eles podem ocultar as altas taxas de abandono ainda para os próprios administradores dos programas.

Tabela 1. Percentual de alunos por anos de prática

\begin{tabular}{c|c|c}
\hline Anos de prática & Sujeitos & $\mathbf{\%}$ \\
\hline Até 1 & 4338 & 79,42 \\
\hline $1-2$ & 871 & 15,95 \\
\hline $2-3$ & 177 & 3,24 \\
\hline $3-4$ & 59 & 1,08 \\
\hline $4-5$ & 16 & 0,29 \\
\hline $5-6$ & 1 & 0,02 \\
\hline & $\mathbf{5 4 6 2}$ & $\mathbf{1 0 0}$
\end{tabular}

Um dos critérios para a inscrição no programa em pauta que é partilhado por muitos programas em execução era a obrigação do participante de estar matriculado em uma escola, no caso, da rede municipal de ensino. Pode-se entender que este requisito, bastante difundido entre os programas, funciona como uma espécie de reforço ou de prêmio à escolarização regular. A aplicação do critério de forma rígida provocaria uma dupla exclusão, tanto dos que estivessem fora da rede escolar municipal, porém em outra rede (estadual, privada ou comunitária) quanto daqueles que estivessem fora da escola. Contudo,

Movimento, Porto Alegre, v. 15, n. 03, p. 145-162, julho/setembro de 2009. 
o requisito não se aplicava de forma rígida e, assim, alunos da rede estadual e particular se inscreviam no programa para praticar as atividades oferecidas. Contudo, a vigência do critério não permite deduzir qual seria a distribuição da matrícula caso ele não existisse ou se aceitasse participantes de qualquer rede. ${ }^{3}$ Na prática, o critério foi flexibilizado de tal maneira que 3,3\% dos participantes declararam ser da comunidade ou que não apresentaram informação sobre a situação escolar. Portanto, pessoas sem vínculo com qualquer rede de ensino também puderam se inscrever, o que poderia possibilitar um trabalho de recondução para a educação formal. Sabe-se, por registros de campo, que alguns dos participantes voltaram para a educação formal. Carece-se, no entanto, de uma informação confiável para estabelecer seu significado estatístico. No total, aproximadamente $7 \%$ dos participantes não pertenciam à rede municipal. A flexibilidade do programa, para se adequar ao nível local, deve ser apontada como um traço positivo, pois permite a abertura para demandas não presentes nos objetivos. Por vezes, a coordenação do PIS ou seus professores, funcionaram como mediadores nas dificuldades ocorridas entre os alunos e algumas escolas, em casos de abandono ou falta de vagas, intercedendo junto aos diretores das escolas ou na Coordenadoria Regional de Educação para encontrar alguma solução ao problema. A ideia principal a ser resgatada é sobre a importância de que os programas pensem a partir de um Sistema Nacional de Educação, para não realizar exclusões injustificadas e, se tiver entre seus objetivos a reinserção escolar, que seus processos sejam explícitos e acompanhados com o intuito de realimentar as ações. A distribuição pode ser observada na Tabela 2.

Tabela 2. Matrículas no PIS por rede de ensino

\begin{tabular}{c|c|c}
\hline Escola & Alunos & $\mathbf{\%}$ \\
\hline Municipal & 6462 & 93,2 \\
\hline Estadual & 155 & 2,2 \\
\hline Particular & 93 & 1,3 \\
\hline Comunidade & 156 & 2,3 \\
\hline S/informação & 66 & 1,0 \\
\hline TOTAL & $\mathbf{6 9 3 2}$ & $\mathbf{1 0 0}$ \\
\hline
\end{tabular}

${ }^{3} \mathrm{~A}$ existência do critério aponta para as dificuldades de se ter um sistema nacional de educação, preocupação do próprio MEC. A carência da crença no sistema, produto de um longo processo, implica que se possa fazer um programa alternativo ou complementar apenas para a rede municipal.

Movimento, Porto Alegre, v. 15, n. 03, p. 145-162, abril/junho de 2009. 


\section{Artigor Orifimair José Vianna, Hugo Lovisolo}

A participação nas atividades do PIS pareceria estar afetada pelas possibilidades de deslocamento que, de modo geral, está condicionada pela distância e pela idade. Supõe-se que a menor distância entre a moradia e o local das atividades elevaria a possibilidade de participação que também aumentaria com a idade e os decorrentes ganhos de autonomia para se movimentar. Ao observar-se a participação, sob o ângulo da idade, pode-se constatar que, a partir de sete anos de idade, ocorreu um aumento progressivo no número de sujeitos inscritos, aproximadamente $1 \%$. Esta elevação sofre um salto de 3\% na passagem de nove para dez anos de idade, quando as crianças passam a sair de casa sem a presença de responsáveis e a observação direta permite afirmar que aumenta o deslocamento em companhia de colegas ou do irmão mais velhos. ${ }^{4}$

Verificou-se que a maior incidência de indivíduos no PIS encontra-se na faixa etária de 10 a 13 anos - 49,3\%, quando as crianças e jovens já gozam de maior liberdade para andarem sozinhas pela comunidade. De 13 para 14 e de 14 para 15 anos de idade, verificou-se quedas respectivas de aproximadamente 2,5 pontos percentuais, havendo uma diminuição no número de participantes com o avançar da idade. Pode-se entender, na mesma linha de interpretação, que a maior idade e maior liberdade de deslocamento dentro e fora da comunidade outras possibilidades se abrem, tanto na esfera das atividades esportivas quanto na do trabalho e do estudo. Em vários sentidos, a competência de deslocamento pode ir contra a permanência no programa: a reserva da clientela imposta pelas restrições de deslocamento desaparece. Sob outro ponto de vista, deslocar-se para realizar atividades esportivas fora da comunidade pareceria indicar certo descontentamento com a oferta local das mesmas. Assim, a curva de aumento da saída a partir de determinada idade deve servir como alerta para os administradores sobre os níveis de satisfação com o programa.

\footnotetext{
${ }^{4} \mathrm{O}$ deslocamento pelas ruas da comunidade amplia o círculo dos conhecidos e as possibilidades de se apropriarem dos códigos e sinais que lhes indicam segurança ou risco nos momentos de tranquilidade ou conflito na comunidade. Passam a conhecer e se fazem conhecidos pelos moradores e pelos bandidos do local. Identificam os locais e horários mais ou menos apropriados para passar ou ficar. O cotidiano da participação nos projetos implica avaliar a situação, sob o ponto de vista dos riscos do deslocamento.
}

vovimento, Porto Alegre, v. 15, n. 03, p. 145-162, julho/setembro de 2009. 
No caso do programa em foco, a saída pode ser entendida como "desinclusão", no campo do esporte, a partir de decisões individuais. Parece ser importante pesquisar os motivos de tais decisões que aparentam envolver desde o fracasso escolar, por sucessivas repetências, à inserção no mercado de trabalho formal ou informal, a cooptação pelo mundo do tráfico, as demandas da vida doméstica ou familiar e a decepção ou frustração com o esporte, sobretudo quando existia expectativa de profissionalização, entre outras. ${ }^{5}$ Os administradores e agentes dos programas deveriam contar com explicações testáveis sobre os motivos e as decisões que comandam a saída.

Tabela 3. Número de matriculados por idade.

\begin{tabular}{|c|c|c|c|c|c|c|c|c|}
\hline Ano & 1998 & 1999 & 2000 & 2001 & 2002 & 2003 & TOTAL & $\%$ \\
\hline \multicolumn{9}{|c|}{ Idade } \\
\hline 5 & 15 & 4 & & & 1 & 2 & 22 & 0,3 \\
\hline 6 & 71 & 31 & 8 & & 27 & 34 & 171 & 2,6 \\
\hline 7 & 80 & 123 & 77 & 37 & 54 & 78 & 449 & 6,8 \\
\hline 8 & 98 & 113 & 95 & 60 & 89 & 86 & 541 & 8,2 \\
\hline 9 & 113 & 138 & 102 & 47 & 106 & 109 & 615 & 9,3 \\
\hline 10 & 151 & 214 & 121 & 61 & 118 & 137 & 802 & 12,1 \\
\hline 11 & 172 & 278 & 140 & 52 & 124 & 145 & 911 & 13,7 \\
\hline 12 & 156 & 325 & 104 & 35 & 91 & 118 & 829 & 12,5 \\
\hline 13 & 118 & 328 & 92 & 37 & 60 & 96 & 731 & 11,0 \\
\hline 14 & 95 & 275 & 62 & 28 & 34 & 67 & 561 & 8,5 \\
\hline 15 & 43 & 249 & 62 & 9 & 13 & 34 & 410 & 6,2 \\
\hline 16 & 32 & 132 & 34 & 10 & 15 & 20 & 243 & 3,7 \\
\hline 17 & 11 & 81 & 24 & 8 & 8 & 8 & 140 & 2,1 \\
\hline 18 & 10 & 46 & 17 & 8 & 10 & 12 & 103 & 1,6 \\
\hline 19 & 1 & 27 & 10 & 1 & 5 & 4 & 48 & 0,7 \\
\hline 20 & & 9 & 9 & 2 & 3 & 3 & 26 & 0,4 \\
\hline 21 & & 5 & 1 & & & 5 & 11 & 0,2 \\
\hline 22 & & & 4 & 1 & 2 & 2 & 9 & 0,1 \\
\hline 23 & & 1 & 1 & & & & 2 & 0,03 \\
\hline \multirow[t]{2}{*}{24} & & & 4 & & & & 4 & 0,06 \\
\hline & & & & & & TOTAL & 6628 & 100 \\
\hline
\end{tabular}

${ }^{5}$ Parcialmente, essa tarefa foi realizada por Vianna (2007).

Movimento, Porto Alegre, v. 15, n. 03, p. 145-162, abril/junho de 2009. 
Uma observação significativa é a da participação no PIS por série escolar. ${ }^{6}$ As escolas municipais atendem a alunos desde a Educação Infantil (EI) até a oitava série do ensino fundamental. No entanto, existe uma concentração de matriculas no PIS, de alunos das primeiras séries do ensino básico. A quantidade de alunos na educação infantil e na classe de alfabetização $(5,7 \%)$ somados aos alunos de primeira a quarta série correspondem a $67,1 \%$ do total de alunos inscritos no período de 1998 a 2003, sendo que a moda da distribuição situa-se nos matriculados que cursam a terceira série quase $22 \%$ do total. O número de participantes decresce de forma importante nas séries seguintes, sendo que os matriculados que cursam da quinta até a oitava série representam $32 \%$ do total. Os matriculados que cursam o ensino médio totalizaram $0,9 \%$.

Tabela 4. Número de matriculados por série

\begin{tabular}{c|c|c|c|c|c|c|c|c}
\hline Ano & $\mathbf{1 9 9 8}$ & $\mathbf{1 9 9 9}$ & $\mathbf{2 0 0 0}$ & $\mathbf{2 0 0 1}$ & $\mathbf{2 0 0 2}$ & $\mathbf{2 0 0 3}$ & TOTAL & $\mathbf{\%}$ \\
\hline $\mathbf{1}^{\mathbf{0}}$ Grau & & & & & & & & \\
\hline EI & 32 & 57 & 2 & 1 & 9 & 21 & 122 & 1,9 \\
\hline CA & 75 & 139 & 17 & 1 & 5 & 9 & 246 & 3,8 \\
\hline 1 & 128 & 251 & 91 & 51 & 66 & 71 & 658 & 10,2 \\
\hline 2 & 147 & 306 & 106 & 56 & 72 & 89 & 776 & 12,01 \\
\hline 3 & 212 & 416 & 222 & 103 & 224 & 241 & 1418 & 21,95 \\
\hline 4 & 211 & 399 & 114 & 57 & 157 & 174 & 1112 & 17,21 \\
\hline 5 & 143 & 325 & 132 & 50 & 119 & 142 & 911 & 14,1 \\
\hline 6 & 74 & 214 & 96 & 28 & 93 & 101 & 606 & 9,43 \\
\hline 7 & 58 & 131 & 56 & 28 & 39 & 48 & 360 & 5,57 \\
\hline 8 & 32 & 73 & 32 & 5 & 28 & 21 & 191 & 2,95 \\
\hline E. M. & & & & & & & & \\
\hline 1 & 1 & 3 & 6 & 1 & 5 & 3 & 19 & 0,3 \\
\hline 2 & 1 & 2 & 9 & 4 & 3 & 6 & 25 & 0,4 \\
\hline 3 & & 1 & 7 & 1 & 1 & 4 & 14 & 0,21 \\
\hline TOTAL & $\mathbf{1 1 1 4}$ & $\mathbf{2 3 1 7}$ & $\mathbf{8 9 0}$ & $\mathbf{3 8 6}$ & $\mathbf{8 2 1}$ & $\mathbf{9 3 0}$ & $\mathbf{6 4 5 8}$ & $\mathbf{1 0 0}$ \\
\hline & & & & & & \\
\hline
\end{tabular}

\footnotetext{
${ }^{6}$ O leitor poderá constatar que as diferenças de matrícula entre os anos são enormes. Em 1999 passa dos 2300 matriculados, enquanto que, em 2001, não chega a 400. Em outro trabalho, Vianna e Lovisolo (2005) trataram especificamente da dinâmica que podem estar subjacentes aos altos e baixos na matrícula anual.
}

vovimento, Porto Alegre, v. 15, n. 03, p. 145-162, julho/setembro de 2009. 
Vejam-se algumas das relações entre série e idade a partir da matrícula no PIS. Podem-se observar os indícios do fracasso escolar na tabela que compara o número de matrículas dos inscritos no PIS por idade e por série escolar. Embora tenha ocorrido uma elevação no número de inscritos por idade, a curva de inscritos por série não seguiu o mesmo padrão, determinando diferenças significativas em termos das proporções de participação por idade e série. Observe-se especialmente a terceira série, na qual deveriam estar os alunos com nove anos idade - correspondendo a 10,9\% de matrículas, verifica-se mais do dobro de declarações na série $(22,2 \%)$. Observe-se que nos casos dos matriculados de 14 anos (10\%) representam apenas 3\% dos alunos na oitava série. A terceira e quarta séries parecem representar o gargalo da progressão escolar para os alunos inscritos no PIS. A partir dos 11 anos, quando deveriam estar na quinta série, a relação idade/série escolar mostra-se mais equilibrada, contudo, a Tabela 5 mostra a não sincronia funcionando: alunos com mais idade real do que a ideal por série.

Uma pergunta central para a avaliação dos programas de inclusão seria: eles incidem sobre a regulação da idade/série? Este pareceria ser um critério de avaliação dos programas que não apenas deveriam incidir sobre a retenção dos alunos na escola, porém, também, sobre a regulação da relação, ainda mais quando os programas operam com aulas de apoio, extraclasse ou de reforço.

Tabela 5. Relação entre idade e série dos alunos

\begin{tabular}{c|c|c|c}
\hline Idade & $\mathbf{\%}$ & Série & $\mathbf{\%}$ \\
\hline 5 & 0,4 & EI & 1,9 \\
\hline 6 & 3,0 & CA & 3,8 \\
\hline 7 & 8,0 & 1 & 10,3 \\
\hline 8 & 9,6 & 2 & 12,1 \\
\hline 9 & 10,9 & 3 & 22,2 \\
\hline 10 & 14,2 & 4 & 17,4 \\
\hline 11 & 16,2 & 5 & 14,2 \\
\hline 12 & 14,7 & 6 & 9,5 \\
\hline 13 & 13,0 & 7 & 5,6 \\
\hline 14 & 10,0 & 8 & 3,0 \\
\hline
\end{tabular}

Movimento, Porto Alegre, v. 15, n. 03, p. 145-162, abril/junho de 2009. 


\section{Antifor Orifinais}

José Vianna, Hugo Lovisolo

Sob o ponto de vista do gênero, as proporções da participação masculina e feminina são significativas para avaliar a incidência diferenciada do programa. A diferença entre a presença masculina e a feminina aumentou conforme os anos de permanência. Até os dois anos, a participação masculina é superior à feminina, porém, menos de $20 \%$. Dos alunos que permaneceram por três anos, as jovens correspondiam a menos de $50 \%$ dos jovens e a um terço da participação total. A regra parece indicar que quanto maior tempo de prática menor a participação feminina. Veja-se a distribuição por tempo de permanência ou anos de prática, na Tabela 6 .

Tabela 6. Sujeitos por anos de prática e gênero

\begin{tabular}{c|c|c|c|c}
\hline \multirow{2}{*}{$\begin{array}{c}\text { Anos de } \\
\text { prática }\end{array}$} & Sujeitos & M & F & inform. \\
\hline Até 1 & 4338 & 2332 & 1981 & 25 \\
\hline $1-2$ & 871 & 463 & 405 & 3 \\
\hline $2-3$ & 177 & 119 & 57 & 1 \\
\hline $3-4$ & 59 & 42 & 17 & 0 \\
\hline $4-5$ & 16 & 13 & 3 & 0 \\
\hline $5-6$ & 1 & 1 & 0 & 0 \\
\hline TOTAL & $\mathbf{5 4 6 2}$ & $\mathbf{2 9 7 0}$ & $\mathbf{2 4 6 3}$ & $\mathbf{2 9}$ \\
\hline
\end{tabular}

As razões do declínio da participação feminina merecem ser exploradas com maior detalhe. Diante da questão, os participantes do programa, agentes e jovens, de praxe, apontam para as tarefas domésticas e, algumas vezes, para a gravidez como razões para o abandono. Há, no entanto, dados assistemáticos de campo que indicariam visões ou expectativas diferenciadas em relação às práticas esportivas e sobre as quais os programas poderiam ter incidência. É voz corrente entre os professores de educação física escolar que, a partir da quinta série, emerge a resistência às aulas, sendo, sobretudo, uma atitude com maior peso entre as meninas. Relações diferenciadas com o corpo também envolvem a infraestrutura de vestiários e banheiros, pois, segundo alguns depoimentos, as meninas não desejam sair das atividades suadas e sentindo-se sujas. Há também a incidência da modalidade esportiva e as expectativas diferenciadas que se lhes associam. Um bom exemplo são as artes marciais, em que a escalada

Movimento, Porto Alegre, v. 15, n. 03, p. 145-162, julho/setembro de 2009. 
do aprendizado é salientada no próprio uniforme e pode conduzir a que o praticante se torne mestre no esporte. Está apenas apresentando-se algumas sugestões de possíveis encaminhamentos para se entender a participação diferenciada feminina que, no entanto, deveria fazer sentido no contexto da participação geral.

\section{CONSIDERAÇÕES FINAIS}

Interessa registrar as conclusões de modo a que funcionem como recomendações para refinar o acompanhamento dos programas.

Muitos projetos da iniciativa pública e privada apresentam semelhanças com o PIS investigado. Os dados quantitativos divulgados na mídia, sites e fôlderes promocionais, ressaltam a participação crescente de crianças e jovens sem considerar a evasão que, na maioria dos casos, se inicia nos primeiros meses de atividade. As informações levam a crer que o sucesso é sobre-estimado, enquanto o fracasso e suas causas são pouco considerados. Dever-se-á realizar pesquisas comparativas entre os que permanecem por alguns anos nos programas e os que saem antes de cumprir um semestre e um ano. Em outras palavras: como são provocadas a "saída" e a "lealdade", na terminologia proposta por Hirschman (1973) ao programa em foco.

Os mecanismos da "saída" deveriam ser privilegiados de alguma maneira pelo sistema de dados de acompanhamento das atividades. O primeiro dado importante seria o registro das saídas, impossibilitando que fique oculto na taxa mais ou menos constante da matrícula. Em segundo lugar, os programas deveriam entender também os mecanismos de re-ingresso, impossibilitar que se torne apenas matrícula nova.

As diversas instituições públicas e privadas, que utilizam as atividades esportivas para minimizar os "riscos" na vida de crianças e jovens pobres, estreitamente associadas às influências supostamente negativas da rua, ainda parecem supor que a participação dos indivíduos nessas atividades, como direito social ou inclusão, seja suficiente para que tenham uma vivência de socialização positiva e de cidadania. O tempo total de participação, o rodízio de entrada e saída, a exploração das modalidades esportivas pelos participantes parecem ser variáveis importantes para considerar os efeitos dos programas.

Movimento, Porto Alegre, v. 15, n. 03, p. 145-162, abril/junho de 2009. 


\section{Antigor Orifinais}

José Vianna, Hugo Lovisolo

A relação entre objetivos, estratégias e procedimentos na avaliação do impacto social nem sempre podem ser facilmente observada. Investigação realizada por Zaluar (1994), em bases etnográficas, observou que os projetos pautados na espontaneidade e nas experiências fortuitas, não atendiam as expectativas dos alunos a partir dos 14 anos de idade, quando possivelmente está em pauta a inserção no mundo do trabalho e também a maior incidência de envolvimento de jovens com o crime organizado. A observação de que os projetos acabem funcionando como depósitos de crianças, cumprindo o propósito de retirá-las das ruas por um período de tempo relativamente curto, insuficiente para envolvê-las em um processo relevante de socialização, não deveria ser negligenciada.

Ter vontade de refinar o entendimento dos programas, dando conta de processos nem sempre observáveis no cotidiano, que se refletem nas altas taxas de abandono, implicaria uma capacitação muito especial de dirigentes e agentes sociais. Ao que tudo indica, a eficiência dos programas passa pela construção de acordos entre as propostas institucionais e as expectativas dos participantes, sem o qual os investimentos públicos e privados e as boas intenções de seus idealizadores podem resultar em impacto aquém da expectativa. Assim, conhecer as racionalidades locais e as expectativas dos participantes, deveria ser um elemento chave para a otimização do processo de inclusão social através da educação física, do esporte e do lazer.

Social inclusion through sports project: notes
about the evaluation
Abstract: The projects of sports objectives are
oriented by the social inclusion. Based on researches
already made about of the participation of children and
youngsters from popular layers in sports - taking as
main empirical field the Social Inclusion Project (PIS),
located at Cidade de Deus, Rio de Janeiro - proposes
to analyze and discuss the value of the administrative
data of the programs to give accountability of relevant
problems (ones of membership application and turnover).
It is to reflect and show ways to refine the gathered
data of the programs. The experience counted with a
significant empirical base, quantitative and temporal:
6932 application forms, referring to 5642 students.
Keywords: Sports. Social inequity. Evaluation.

Movimento, Porto Alegre, v. 15, n. 03, p. 145-162, julho/setembro de 2009. 


\begin{abstract}
Proyecto de inclusión social a través del deporte: notas sobre a evaluación.

Resumen: Los objetivos de los proyectos deportivos (niños y jóvenes) son orientados para la inclusión social. A partir de investigaciones realizadas sobre la participación en camadas populares - tomando como campo empírico principal el "Proyecto de Inclusão Social" (PIS), situado en la "Cidade de Deus", Río de Janeiro - se propone analizar y discutir el valor de los datos administrativos de los programas para dar cuenta de problemas relevantes (adhesión y rotatividad). Tratase de reflexionar y apuntar caminos de refinamiento de los datos administrativos. La experiencia contó con una base significativa, cuantitativa y temporal, 6.932 fichas de inscripciones referentes a 5.462 . Palabras clave: Deportes. Inequidad social. Evaluación.
\end{abstract}

\title{
REFERÊNCIAS
}

BORGES, C. N. F. Um só coração e uma só alma: as influências da ética romântica na intervenção educativa salesiana e o papel das atividades corporais. Tese (Doutorado) - Curso de Educação Física, Universidade Gama Filho. Rio de Janeiro, 2005.

DANISH, S. J.; NELLEN, V. C. New roles for sport psychologists: teaching li skills through sport to at-risk youth. Quest, Champaign, v. 49, n. 100-113, 1997.

ELIAS, N.; DUNNING, E. A busca da excitação. Lisboa: DIFEL, 1992.

GOMES, M. C.; CONSTANTINO, M. T. Projetos esportivos de inclusão social: PIS crianças e jovens. In: COSTA, L. P. da. (ed.) Atlas do esporte no Brasil. Rio de Janeiro: Shape, 2005, p. 602-611.

HIRSCHMAN, A. Saída, voz e lealdade. São Paulo: Perspectiva, 1973.

LOVISOLO, H. Educação física: a arte da mediação. Rio de Janeiro: Sprint, 1995.

LOVISOLO, H. Atividade física e saúde, uma agenda sociológica de pesquisa. In: MOREIRA, W.; SIMÕES, R. (Org.). Esporte como fator de qualidade de vida. São Paulo: Unimep, 2002a.

LOVISOLO, H. Um homem chamado cavalo: notas sobre a socialização. In: ARNT, H.; HELAL, R. (Orgs.). A sociedade na tela do cinema. Rio de Janeiro: E-papers Serviços Editoriais, 2002b. p. 9-18.

SILVA, L. H. O. Igreja Católica, atividades corporais e esportes: superando preconceitos. Tese (Doutorado) - Curso de Educação Física, Universidade Gama Filho. Rio de Janeiro, 2002.

Movimento, Porto Alegre, v. 15, n. 03, p. 145-162, abril/junho de 2009. 


\section{Artigor Orifinais José Vianna, Hugo Lovisolo}

SILVA MELLO, A.; LOVIOSLO, H. L.; VOTRE, S. J. Discourse analysis of engaged e and disengaged members of the "Esporte Cidadão" Project. Fiep Bulletin, Genebra: Special Ed., v. 28, p. 459-462, 2008.

SOARES, C.; DUARTE, D. Dados e resultados do projeto: medidas sócio-educativas e pesquisa entre jovens em conflito com a lei. In: SENTO-SÉ, J.T.; PAIVA, V. (Org.). Juventude em conflito com a lei. Rio de Janeiro: Garamondo, 2007.

TUBINO, M.G. Dimensões sociais do esporte. 2. ed. São Paulo: Cortez, 2001.

VIANNA, J.A. Educação física, esportes e lazer para as camadas populares: a representação social dos seus atores. In: CONGRESSO BRASILEIRO DE CIÊNCIAS DO ESPORTE (13., 2003, Caxambu). Anais... Campinas: CBCE, 2003. [recurso eletrônico].

VIANNA, J.A.; LOVISOLO, H. Educational sports: the adhesion from the subjects of popular layers. Fiep Bulletin, Genebra: Special Ed, v. 75, p. 487-490, 2005.

VIANNA, J. A. Esportes e camadas populares: inclusão e profissionalização. Tese (Doutorado) - Programa de Pós-Graduação em Educação Física, Universidade Gama Filho. Rio de Janeiro, 2007.

ZALUAR, A. Cidadãos não vão ao paraíso: juventude e política social. Rio de Janeiro: Escuta, 1994.

Recebido em: 31.07 .2008

Aprovado em: 16.02.2009

Movimento, Porto Alegre, v. 15, n. 03, p. 145-162, julho/setembro de 2009. 